AperTO - Archivio Istituzionale Open Access dell'Università di Torino

\title{
Mesothelioma families without inheritance of a BAP1 predisposing mutation
}

\section{This is the author's manuscript}

Original Citation:

\section{Availability:}

This version is available http://hdl.handle.net/2318/1606240

since 2016-10-20T16:18:26Z

Published version:

DOI:10.1016/j.cancergen.2016.07.002

Terms of use:

Open Access

Anyone can freely access the full text of works made available as "Open Access". Works made available under a Creative Commons license can be used according to the terms and conditions of said license. Use of all other works requires consent of the right holder (author or publisher) if not exempted from copyright protection by the applicable law. 


\section{Accepted Manuscript}

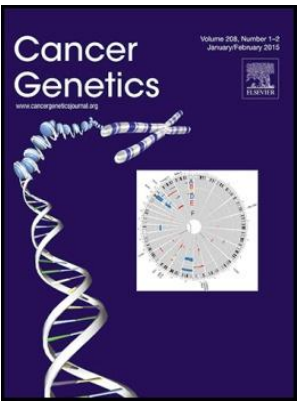

Title: Mesothelioma families without inheritance of a $B A P 1$ predisposing mutation

Author: Valeria Ascoli, Ilaria Cozzi, Simona Vatrano, Stefania Izzo, Jessica Giorcelli, Elisa Romeo, Caterina Carnovale-Scalzo, Lucia Rosalba Grillo, Francesco Facciolo, Paolo Visca, Mauro Papotti, Luisella Righi

PII: S2210-7762(16)30221-6

DOI: http://dx.doi.org/doi: 10.1016/j.cancergen.2016.07.002

Reference: CGEN 480

To appear in: $\quad$ Cancer Genetics

Received date: $\quad 29-4-2016$

Revised date: $\quad$ 14-7-2016

Accepted date: $15-7-2016$

Please cite this article as: Valeria Ascoli, Ilaria Cozzi, Simona Vatrano, Stefania Izzo, Jessica Giorcelli, Elisa Romeo, Caterina Carnovale-Scalzo, Lucia Rosalba Grillo, Francesco Facciolo, Paolo Visca, Mauro Papotti, Luisella Righi, Mesothelioma families without inheritance of a BAPl predisposing mutation, Cancer Genetics (2016), http://dx.doi.org/doi: 10.1016/j.cancergen.2016.07.002.

This is a PDF file of an unedited manuscript that has been accepted for publication. As a service to our customers we are providing this early version of the manuscript. The manuscript will undergo copyediting, typesetting, and review of the resulting proof before it is published in its final form. Please note that during the production process errors may be discovered which could affect the content, and all legal disclaimers that apply to the journal pertain. 


\section{Mesothelioma Families without Inheritance of a BAP1 Predisposing Mutation}

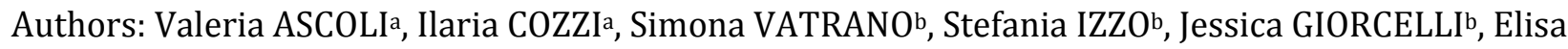
ROMEOc, Caterina CARNOVALE-SCALZOc, Lucia Rosalba GRILLOd, Francesco FACCIOLOe, Paolo VISCAf, Mauro PAPOTTIg, Luisella RIGHI ${ }^{\mathrm{b}}$

aDepartment of Radiological, Oncological and Anatomo-Pathological Sciences, Sapienza University, Viale Regina 324-00161 Rome, Italy

bDepartment of Oncology, San Luigi Hospital, University of Turin, Regione Gonzole, 10- 10043 Orbassano, Italy

cDepartment of Epidemiology, Lazio Regional Health Service, Via Cristoforo Colombo, 112 - 00147 Rome, Italy

dDepartment of Pathology, San Camillo Hospital, Circonvallazione Gianicolense 87 - 00152 Rome, Italy eDepartment of Oncologic Thoracic Surgery, Regina Elena Cancer Institute, Via Elio Chianesi, 53-00144 Rome, Italy

fDepartment of Pathology, Regina Elena Cancer Institute, Via Elio Chianesi, 53-00144 Rome, Italy gDepartment of Oncology, Pathology Unit, AOU Città della Salute e della Scienza, University of Turin, Corso Bramante 88- 10126 Turin, Italy

Ilaria Cozzi

Simona Vatrano

Stefania Izzo

Jessica Giorgelli

Elisa Romeo (ilaria.cozzi.ic@gmail.com)

(simona.vatrano@unito.it) (stefaniaizzo_1990@libero.it)

(gio.jessica@gmail.com)

(e.romeo@deplazio.it) 
Caterina Carnovale-Scalzo

Lucia Rosalba Grillo

Francesco Facciolo

Paolo Visca

Mauro Papotti

Luisella Righi (caterinacarnovalescalzo@gmail.com)

(lgrillo@scamilloforlanini.rm.it)

(facciolo@ifo.it)

(visca@ifo.it)

(mauro.papotti@unito.it)

(luisella.righi@unito.it)

\section{Submitting and corresponding author:}

Professor Valeria ASCOLI

Department of Radiological, Oncological and Anatomo-Pathological Sciences, Sapienza University, Rome-Italy

Viale Regina Elena, 324 - 00161 Rome, Italia

valeria.ascoli@uniroma1.it

tel.+39-06-44703550; +39-06-49973397; fax +39-06-49979175

\section{Running title:}

BAP1-unmutated Familial Mesothelioma 


\section{Abstract}

Familial malignant mesothelioma clusters are ideal candidates to explore BAP1 genomic status as a predisposing risk factor. We report data on $B A P 1$ analysis in four families with multiple mesothelioma cases to investigate possible $B A P 1$ alterations associated with an inherited cancer syndrome. We also recorded family history of cancer and assessed asbestos exposure. By genomic direct sequencing, we found no evidence of a BAP1 germline mutation in tumor DNA samples (one mesothelioma per family: $\mathrm{n}=3$ epithelioid; $\mathrm{n}=1$ biphasic). On the other hand, we identified a novel $B A P 1$ somatic alteration (c.329_335delinsTC) in exon 5 ( $\mathrm{n}=1$ biphasic), and we hypothesized the occurrence of somatic inactivating events not identifiable by sequencing in the other cases ( $\mathrm{n}=3$ epithelioid), as demonstrated by the loss of nuclear BAP1 immunostaining. History of other cancers was in sites not typical of the BAP1 cancer syndrome. Asbestos exposure was occupational ( $\mathrm{n}=2$ clusters), household $(\mathrm{n}=1)$, and unknown $(\mathrm{n}=1)$. These family units without inheritance of a BAP1 predisposing mutation expand the number of unmutated germline BAP1 families with multiple mesothelioma cases. This suggests that besides the exposure to asbestos other currently unknown genetic or epigenetic factors may be responsible for the high incidence of mesothelioma in BAP1-unmutated families.

Key words: malignant mesothelioma; asbestos; familial cancer; $B A P 1$ germline mutation; $B A P 1$ somatic mutation 


\section{Introduction}

Malignant mesothelioma (MM) occurs as sporadic cancer (one affected individual in the family) generally in association with asbestos exposure. Its occurrence as clusters among blood-relatives (two or more individuals are affected) suggests increased genetic susceptibility.

BAP1 (BRCA1-associated protein 1) is a tumor suppressor gene located on chromosome 3p21.1, encoding for a deubiquitinating enzyme that requires nuclear localization [1]. BAP1 regulates cell cycle control, target genes transcription, and DNA damage repair [2]. The germline mutation in the BAP1 gene is associated with a hereditary tumor predisposition syndrome (BAP1-TPDS, OMIM\#614327) that occurs in family members with several cancer types: MM, uveal/cutaneous melanoma, renal cell carcinoma, basal cell carcinoma and other cancers [3-16]. As of March 2016, forty-six families with multiple cases of MM have been analyzed for BAP1 germline alterations. Some families were proven to carry $B A P 1$ germline alterations in association with family history of either typical BAP1-TPDS cancers [9, 10,17] or not typical BAP1-TPDS cancers $[9,10,18,19]$. In addition, families with multiple cases of MM without inheritance of a predisposing germline BAP1 mutation have been reported [20]. Germline mutations described to date are nucleotide-level mutations.

Germline $B A P 1$ alterations are a rare event in sporadic MM [10, 18, 21-23]. The majority are benign polymorphisms (SNPs) or variants of unknown significance (VUS) [4, 5, 23]. Those of pathogenic significance have been described in association with BAP1-TPDS malignancies $[4,21,24-$ 28]. On the other hand, somatic mutations of $B A P 1$ are a frequent event in $M M[26,28,29]$, with a variable rate of occurrence depending on the molecular assay used. Somatic mutations described to date are both nucleotide-level and chromosomal mutations [30].

MM familial clusters among blood-relatives are ideal candidates to identify BAP1 germline carriers associated with the putative BAP1 cancer syndrome. Familial mesothelioma is defined by the diagnosis of two or more blood-relatives affected by MM. Over the past 30 years, we have detected 13 MM familial clusters in a population-based study [19]. One of these, an asbestos-exposed family with multiple cases of pleural MM and without inheritance of a predisposing BAP1 mutation has been recently reported [30]. We have decided to investigate further if additional MM clusters are associated or not with inheritance of a $B A P 1$ germline mutation. 


\section{Materials and Methods}

Familial cases and Samples

Families were identified through a regional section of the Italian network of the Mesothelioma Registry (www.deplazio.net) and a pathology-based archive. We selected 4 clusters (family C, D, G, and 0) whose pedigrees were previously reported [30] on the basis of availability of samples from at least two first-degree relatives with MM. Peripheral blood samples were unavailable, and only limited formalin-fixed paraffin-embedded (FFPE) tissues specimens were available for mutational and immunohistochemical (IHC) studies. As indicator of a genetic predisposition to cancer, we assessed personal and family history of other primary malignancies that was positive in 3 families (stomach, pancreas, lung, prostate, colon). Asbestos exposures were assessed by interviewing patients and/or the next of kin through a standard questionnaire and coded according to a classification relating to modalities of exposure as 'occupational ( $\mathrm{n}=2$ families) household $(\mathrm{n}=1)$ and unknown $(\mathrm{n}=1)$ ' (https://www.inail.it).

\section{Sequencing analysis}

BAP1 mutational analysis was performed on one case for each family considering the index cases [31]. Since DNA was not available from peripheral blood, genomic DNA was obtained from FFPE tissues (3 epithelioid and 1 biphasic MM), using the QIAamp DNA FFPE Tissue Kit (QIAGEN, Valencia, CA) according to the manufacturer's protocol. Neoplastic tissue was selected to be analyzed separately from the normal tissue portions. For all samples, we made sure that the neoplastic cell population was above $80 \%$. Furthermore, the biphasic MM was manually microdissected in the two neoplastic populations (epithelioid and sarcomatoid) that were analyzed separately.

The rationale of the molecular approach was the following: 1) to analyze the tumor-only population in the index case since tumor-only testing can reveal germline mutation $[26,28] ; 2$ ) in the case of a BAP1 mutation detection, to expand the mutational analysis, matching normal and tumor DNA for a correct assessment of a somatic versus a germline mutation; 3 ) in the case of a germline BAP1 mutation, to expand the mutational analysis, sequencing normal DNA of the blood-relative.

The entire BAP1 coding sequence was amplified with primers designed on the flanking intronic/exonic regions using Primer3 software (http://bioinfo.ut.ee/primer3-0.4.0/) Because of the 
fragmentation of DNA fixed in formalin, 32 amplicons were used to amplify small DNA fragments.

Primers and PCR conditions are available on request. Bidirectional Sanger sequencing was performed by an external commercial service using standard protocols (Eurofins MWG Operon, Ebesberg, Germany). Eletropherogram results were analyzed by using FinchTV software (Geospiza, Seattle, WA) and BLASTN tool for alignment analyses to the human reference genome (https://blast.ncbi.nlm.nih.gov/). Putative BAP1 variants were validated via bidirectional resequencing of an independent PCR amplification. Variants were annotated according to the longest isoform RefSeqs from the Genome Reference Consortium Human Build 37.3 (NM_004656.3) and described according to the Human Genome Variation Society guidelines (HGVS, http://www.hgvs.org/mutnomen/). Putative genetic alterations were classified as polymorphism (neutral or germinal) or somatic pathogenic (or of unknown pathogenicity) by considering the following: (1) the reported frequency in the following polymorphic databases: dbSNP (build 131; http://www.ncbi.nlm.nih.gov/projects/SNP/), 1000 Genomes (http://www.1000genomes.org/), NHLBI GO ESP (evs.gs.washington.edu/EVS/);

(2) the presence in somatic mutational COSMIC databases (http://cancer.sanger.ac.uk/cosmic); (3) evolutionary conservation of the involved residue at both nucleotide and amino acid level, calculated by multiple alignments of 46 vertebrate species and (4) in-silico prediction of functional effect by SIFT (http://sift.jcvi.org/), PolyPhen-2 (http://genetics.bwh.harvard.edu/pph2/), SNPs3D

(http://www.snps3d.org/) , Panther (www.pantherdb.org/) , MutPred (http://mutpred.mutdb.org/), NetGene (http://www.cbs.dtu.dk/services/NetGene2/).

Immunohistochemical analysis

IHC detection of BAP1 was performed using a primary anti-human BAP1 antibody (C-4, 1:200, Santa Cruz Biotechnology, Santa Cruz, CA, USA) and an automated immunostainer (BenchMark, Ventana Medical System, Tucson, AZ) on FFPE tumor sections in 8 out 9 MM cases ( 6 epithelioid, 1 sarcomatoid, and 1 biphasic MM). One case (1 sarcomatoid, G-II-9) was not available. Tumor tissues were assessed as positive or negative on the basis of the presence or absence of BAP1 nuclear staining. It was also assessed the staining of the cytoplasm (and intensity, as strong or faint). The fraction of 
BAP1 positive stained cells was evaluated for nuclear and cytoplasmic sub-cellular localization $(<25 \%$,

$25-75 \%$ or $>75 \%$ ). Normal stromal endothelial or lymphoid cells served as positive internal control. 


\section{Results}

BAP1 sequencing and IHC findings are summarized in Table 1 and illustrated in Figures 1 and 2. Sequencing analysis showed no BAP1 gene mutation neither in heterozygosis nor in homozygosis in three of the four index cases analyzed (C-II-2, G-II-6 and O-III-1, all epithelioid MM). Conversely, in the fourth index case (D-II-4, biphasic MM), a complex non-frameshift insertion/deletion (InDel) in exon 5 (c.329_335delinsTC) was detected in heterozygosis, as shown in Figure 2C. This leads to the loss of two aminoacids (p.Pro110_Ser111del) resulting in a shorter BAP1 protein of 727 aminoacids, and involves the UCH (Ubiquitin carboxyl-terminal hydrolase, UniProtKB - Q92560) catalytic domain. This alteration was identified both in the epithelioid and in the sarcomatoid component with two different allelic frequencies. The electropherogram relating to sarcomatoid cells showed clear-cut peak heights lower than those of epitheliod cells (Figure 2C). The mutational analysis of normal tissue from this case lacked the $B A P 1$ alteration, indicating a somatic origin (Figure $2 \mathrm{C}$ ).

By IHC, a complete loss of nuclear BAP1 staining was seen in all epithelioid MM (C-II-1, C-II-2, D-II-3, G-II-6 and O-III-1) and in the epithelioid cells of biphasic MM (D-II-4). BAP1 nuclear immunoreactivity was retained only in the sarcomatoid MM (G-II-8) and in sarcomatoid cells of the biphasic MM (D-II-4), with a variable percentage of stained cells. BAP1 cytoplasmic staining was observed in all epithelioid tumors, with a variable number of stained cells, uneven intensity and a coarse granular pattern. Similarly, BAP1 cytoplasmic staining was observed in the fraction of sarcomatoid cells that lost their nuclear reactivity. 


\section{Discussion}

In the present study, we demonstrated that no germline BAP1 alterations could be identified in the tissues of four families affected by multiple MM, thus speculating that in these individuals there is no evidence of an inheritance linked to BAP1 mutations. The absence of a germline mutation in coding regions and intron-exon boundaries of $B A P 1$ gene was proven in the normal tissue DNA belonging to one index case (D-II-4) and by excluding single point mutations and small InDels in tumor DNA belonging to the other three index cases (C-II-2, 0-III-1, G-II-6). We cannot exclude large deletions of $B A P 1$ that are undetectable by Sanger sequencing $[3,9,11,19]$. However, large deletions of BAP1 have never been detected in germline configuration in families either with multiple MM [3, 9, 11, 32-37] or without MM $[26,28,29]$. The loss of nuclear BAP1 immunostaining suggests that these tumors may harbor somatic alterations of the BAP1 gene, a frequent event in sporadic epithelial MM $[21,24,26$, 27]. Although most $B A P 1$ somatic mutations are nucleotide-level mutations, additional technical approaches would have been necessary to detect gross deletions at exon level. Unfortunately, a limit of the present study includes the unavailability of sufficient amount of tumor DNA to perform a comprehensive analysis of $B A P 1$ gene alterations.

Furthermore, we identified -at the somatic level only- a complex InDel p.Pro110_Ser111del (exon 5) in case D-II-4 that has never been previously reported. This subject had a history of occupational asbestos exposure as his brother (Table 1, case D-II-3). Somatic mutations in exon 5 occur in about $5 \%$ of all tumors (COSMIC; http://cancer.sanger.ac.uk/cosmic) and in $6 \%$ considering sporadic MM, only [38]. This novel BAP1 alteration leads to a probably impaired deubiquitinase activity of BAP1 protein, suggesting its pathogenic role. This hypothesis is supported by in-silico function predictions and by the absence of such $B A P 1$ variant in control populations $(\mathrm{MAF}<0.01)$. Interestingly, the same mutation is present in the DNA of both epithelial and sarcomatoid MM components, with a heterogeneous allelic frequency. Loss of nuclear BAP1 and presence of cytoplasmic staining in epithelial cells is in line with our identified mutation in the UCH domain, which promotes BAP1 cytoplasmic retention [39]. Instead, the retaining of BAP1 nuclear staining in a prevailing fraction of neoplastic spindle cells (Figure 2C and Table 2) is in line with a lower allelic frequency of mutant alleles in sarcomatoid MM DNA compared to that of the epithelial DNA, that might 
be due to an heterogeneous population of mutated and wild type sarcomatoid cells. Alternatively, loss of heterozygosity ( $\mathrm{LOH}$ ) could be taken into account. Indeed, Nasu and co-workers found different and sometimes-coexisting mechanisms of gene alteration in their MM series, depending on the assay used. In two samples, they detected large deletions in one allele by MLPA and nucleotide-level mutations in the other allele by Sanger sequencing, in association with loss of BAP1 nuclear protein by IHC, thus supporting LOH [26]. Cigognetti and co-workers provided evidence of homozygous deletions in association with heterozygous deletions of the BAP1 locus by FISH analysis in a few cases among their IHC BAP1-negative MM series [40]. Intra-tumor differences in BAP1 LOH were recently reported in sarcomatoid and carcinomatous elements in clear renal cell carcinomas [41].

We were not able to find any somatic mutations in the other tumors. However, BAP1 IHC results give us some further information. Loss of BAP1 nuclear staining in association with a cytoplasmic staining could indicate a mutant $B A P 1$ allele $[42,43]$. The accumulation of BAP1 mutant protein in the cell could inactivate the wild-type protein with a consequently altered protein localization and/or loss of function. This is likely due to a dominant-negative effect of the mutant protein, a distinctive characteristic of somatic events of tumor suppressor genes [44], in the same way as also discussed for BAP1 [26]. Failing to detect this mutation by Sanger sequencing is not a surprise, based on the results of Nasu et al. [26] There are several possible explanations. First of all, a large BAP1 deletion (or insertion) which can involve the portion of gene codifying the nuclear localization signal (exons 16-17) or the UCH domain. On the other hand, this large deletion (or insertion) could be associated with LOH of the other allele thus leading to a cytoplasmic accumulation of the BAP1 deleted protein. BAP1 could be modified by post-translational modifications inhibiting its autodeubiquitination activity that lead to a cytoplasmic sequestration of BAP1 mediated by regulatory proteins, without any export signal in $B A P 1$ gene. As a matter of fact, several ubiquitination sites of $B A P 1$ were identified in vitro study by Mashtalir and coworkers [38].

Regarding family members with MM whose DNA was not sequenced (Table 1), by inference we can likely exclude BAP1 germline mutation being first-degree relatives affected by the same cancer of index cases whose tumor DNA was sequenced and found not mutated. IHC findings in three epithelioid MM cases (C-II-1, D-II-3, O-II-3) suggest that the loss of nuclear staining occurred via somatic mutation 
(see Figure 1). BAP1 nuclear staining retained in one sarcomatoid MM (G-II-8) is in agreement with other studies reporting data of positive BAP1 staining on sarcomatoid MM [25] and on the absence of BAP1 mutation $[9,10,18,19]$. Considering all families with multiple cases of MM analyzed to date for BAP1 germline mutations (see Table 2), those described in the present study without a predisposing germline $B A P 1$ mutation are similar to those reported by other investigators $[9,10,19]$. Most familial clusters have asbestos exposure, and a family history of malignancies other than those typical of TPDS [9]. This suggests that other genetic or epigenetic factors may be responsible for the high incidence of MM in these families, besides asbestos exposure. By contrast, most families with multiple cases of MM and with BAP1 germline mutations have typical BAP1-TPDS malignancies (uveal melanoma, skin melanoma, renal cell carcinoma, basal cell carcinoma, etc.) and are heterogeneously linked to asbestos exposure. In our families, no TPDS syndrome malignancies were recorded. In the literature, there are significant differences between unmutated and mutated BAP1 gene families for history of TPDS malignancies $(\mathrm{p}=0.00$, Fisher-Yates test), history of other cancer $(\mathrm{p}=0.014)$, and history of asbestos exposure $(\mathrm{p}=0.008)$. When asbestos exposure is unknown or when this information is missing $[4,6,9$, 19], the differences are of borderline statistical significance $(\mathrm{p}=0.046)$. Heterogeneity of BAP1 status in familial MM (mutated versus unmutated BAP1) can be attributed to a bias in patient recruitment. Investigators have examined $B A P 1$ in families: i) with high incidence of $M M[3,7,9,11,14]$; ii) referred to genetic or cancer centers for uveal melanoma $[9,12,15]$ or other melanocytic tumors $[13,17]$; iii) affected by basal cell carcinoma [16]; iv) having a family history suggestive of the BAP1 cancer syndrome [18]. Other families were examined as part of asbestos surveillance program [10]. Our families were actively searched based on the Italian Mesothelioma Registry, and detected because the proband (index case) and at least one blood-relative were diagnosed with MM according to the Registry available information. Therefore, the recruitment of cases is on a population basis, as those reported by other Italian investigators $[10,18,19]$.

The present study contributes to understanding the role of $B A P 1$ in familial MM, expanding the number of unmutated-BAP1 families, and to suggesting that other genes may determine cancer susceptibility in some familial clusters with multiple MM. Very recently, a large study analyzing 
germline CDKN2A and BAP1 mutations in families with both melanoma and mesothelioma, melanoma (without mesothelioma), mesothelioma (without melanoma) has been published [45]. All BAP1 sequenced families with mesothelioma (but without melanoma) showed a wild-type configuration of the gene and asbestos exposure, in agreement with our present findings. Moreover, the findings in the unmutated-BAP1 families described in this study and in others reported to date provide evidence of the importance of exposure to asbestos (Table 2 and [45]). As far as BAP1 gene is concerned in somatic configuration, these familial MM cases should be considered equivalent to "sporadic" MM, because they harbor non-inherited genomic BAP1 alterations, a common event in MM, especially of the epithelial and biphasic types. 


\section{Acknowledgements}

This work was partially supported by the Lazio Region; the University of Turin; and the Ministry of

Health to the Piemonte Region (Young Researcher 2011 to L.R. grant number: GR-2011-02348356). 


\section{References}

[1] Murali R, Wiesner T, Scolyer RA. Tumours associated with BAP1 mutations. Pathology 2013;45:116-26.

[2] Ladanyi M, Zauderer MG, Krug LM, Ito T, McMillan R, Bott M, Giancotti F. New strategies in pleural mesothelioma: BAP1 and NF2 as novel targets for therapeutic development and risk assessment. Clin Cancer Res 2012;18:4485-90.

[3] Abdel-Rahman MH, Pilarski R, Cebulla CM, Massengill JB, Christopher BN, Boru G, Hovland P, Davidorf FH. Germline BAP1 mutation predisposes to uveal melanoma, lung adenocarcinoma, meningioma, and other cancers. J Med Genet 2011;48:856-9.

[4] Testa JR, Cheung M, Pei J, Below JE, Tan Y, Sementino E, Cox NJ, Dogan AU, Pass HI, Trusa S, Hesdorffer M, Nasu M, Powers A, Rivera Z, Comertpay S, Tanji M, Gaudino G, Yang H, Carbone M. Germline BAP1 mutations predispose to malignant mesothelioma. Nat Genet 2011;43:1022-5.

[5] Carbone M, Ferris LK, Baumann F, Napolitano A, Lum CA, Flores EG, Gaudino G, Powers A, Bryant-Greenwood P, Krausz T, Hyjek E, Tate R, Friedberg J, Weigel T, Pass HI, Yang H. BAP1 cancer syndrome: malignant mesothelioma, uveal and cutaneous melanoma, and MBAITs. J Transl Med 2012;10:179.

[6] Wiesner T, Fried I, Ulz P, Stacher E, Popper H, Murali R, Kutzner H, Lax S, Smolle-Juttner F, Geigl JB, Speicher MR. Toward an improved definition of the tumor spectrum associated with BAP1 germline mutations. J Clin Oncol 2012;30:e337-40.

[7] Wadt K, Choi J, Chung JY, Kiilgaard J, Heegaard S, Drzewiecki KT, Trent JM, Hewitt SM, Hayward NK, Gerdes AM, Brown KM. A cryptic BAP1 splice mutation in a family with uveal and cutaneous melanoma, and paraganglioma. Pigment Cell Melanoma Res 2012;25:815-8.

[8] Ribeiro C, Campelos S, Moura CS, Machado JC, Justino A, Parente B. Well-differentiated papillary mesothelioma: clustering in a Portuguese family with a germline BAP1 mutation. Ann Oncol 2013;24:2147-50.

[9] Popova T, Hebert L, Jacquemin V, Gad S, Caux-Moncoutier V, Dubois-d'Enghien C, Richaudeau B, Renaudin X, Sellers J, Nicolas A, Sastre-Garau X, Desjardins L, Gyapay G, Raynal V, Sinilnikova OM, Andrieu N, Manie E, de Pauw A, Gesta P, Bonadona V, Maugard CM, Penet C, Avril MF, Barillot E, Cabaret O, Delattre O, Richard S, Caron O, Benfodda M, Hu HH, Soufir N, Bressac-de Paillerets B, Stoppa-Lyonnet D, Stern MH. Germline BAP1 mutations predispose to renal cell carcinomas. Am J Hum Genet 2013;92:974-80.

[10] Betti M, Casalone E, Ferrante D, Romanelli A, Grosso F, Guarrera S, Righi L, Vatrano S, Pelosi G, Libener R, Mirabelli D, Boldorini R, Casadio C, Papotti M, Matullo G, Magnani C, Dianzani I. Inference on germline BAP1 mutations and asbestos exposure from the analysis of familial and sporadic mesothelioma in a high-risk area. Genes Chromosomes Cancer 2014;54:51-62.

[11] Pilarski R, Cebulla CM, Massengill JB, Rai K, Rich T, Strong L, McGillivray B, Asrat MJ, Davidorf FH, Abdel-Rahman MH. Expanding the clinical phenotype of hereditary BAP1 cancer predisposition syndrome, reporting three new cases. Genes Chromosomes Cancer 2014;53:177-82.

[12] Rai K, Pilarski R, Cebulla CM, Abdel-Rahman MH. Comprehensive review of BAP1 tumor predisposition syndrome with report of two new cases. Clin Genet 2015.

[13] de la Fouchardiere A, Cabaret O, Savin L, Combemale P, Schvartz H, Penet C, Bonadona V, Soufir N, Bressac-de Paillerets B. Germline BAP1 mutations predispose also to multiple basal cell carcinomas. Clin Genet 2015;88:273-7.

[14] Klebe S, Driml J, Nasu M, Pastorino S, Zangiabadi A, Henderson D, Carbone M. BAP1 hereditary cancer predisposition syndrome: a case report and review of literature. Biomark Res 2015;3:14.

[15] Cheung M, Kadariya Y, Talarchek J, Pei J, Ohar JA, Kayaleh OR, Testa JR. Germline BAP1 mutation in a family with high incidence of multiple primary cancers and a potential geneenvironment interaction. Cancer Lett 2015;369:261-5.

[16] Carbone M, Flores EG, Emi M, Johnson TA, Tsunoda T, Behner D, Hoffman H, Hesdorffer M, Nasu M, Napolitano A, Powers A, Minaai M, Baumann F, Bryant-Greenwood P, Lauk O, Kirschner MB, Weder W, Opitz I, Pass HI, Gaudino G, Pastorino S, Yang H. Combined Genetic and Genealogic Studies Uncover a Large BAP1 Cancer Syndrome Kindred Tracing Back Nine Generations to a Common Ancestor from the 1700s. PLoS Genet 2015;11:e1005633. 
[17] Wadt KA, Aoude LG, Johansson P, Solinas A, Pritchard A, Crainic O, Andersen MT, Kiilgaard JF, Heegaard S, Sunde L, Federspiel B, Madore J, Thompson JF, McCarthy SW, Goodwin A, Tsao H, Jonsson G, Busam K, Gupta R, Trent JM, Gerdes AM, Brown KM, Scolyer RA, Hayward NK. A recurrent germline BAP1 mutation and extension of the BAP1 tumor predisposition spectrum to include basal cell carcinoma. Clin Genet 2015;88:267-72.

[18] Sneddon S, Leon JS, Dick IM, Cadby G, Olsen N, Brims F, Allcock RJ, Moses EK, Melton PE, de Klerk N, Musk AW, Robinson BW, Creaney J. Absence of germline mutations in BAP1 in sporadic cases of malignant mesothelioma. Gene 2015;563:103-5.

[19] Cheung M, Kadariya Y, Pei J, Talarchek J, Facciolo F, Visca P, Righi L, Cozzi I, Testa JR, Ascoli V. An asbestos-exposed family with multiple cases of pleural malignant mesothelioma without inheritance of a predisposing BAP1 mutation. Cancer Genet 2015;208:502-7.

[20] McGregor SM, Dunning R, Hyjek E, Vigneswaran W, Husain AN, Krausz T. BAP1 facilitates diagnostic objectivity, classification, and prognostication in malignant pleural mesothelioma. Hum Pathol 2015;46:1670-8.

[21] Guo G, Chmielecki J, Goparaju C, Heguy A, Dolgalev I, Carbone M, Seepo S, Meyerson M, Pass HI. Whole-exome sequencing reveals frequent genetic alterations in BAP1, NF2, CDKN2A, and CUL1 in malignant pleural mesothelioma. Cancer Res 2015;75:264-9.

[22] Rusch A, Ziltener G, Nackaerts K, Weder W, Stahel RA, Felley-Bosco E. Prevalence of BRCA-1 associated protein 1 germline mutation in sporadic malignant pleural mesothelioma cases. Lung Cancer 2015;87:77-9.

[23] Ohar JA, Cheung M, Talarchek J, Howard SE, Howard TD, Hesdorffer M, Peng H, Rauscher FJ, Testa JR. Germline BAP1 Mutational Landscape of Asbestos-Exposed Malignant Mesothelioma Patients with Family History of Cancer. Cancer Res 2015.

[24] Bott M, Brevet M, Taylor BS, Shimizu S, Ito T, Wang L, Creaney J, Lake RA, Zakowski MF, Reva B, Sander C, Delsite R, Powell S, Zhou Q, Shen R, Olshen A, Rusch V, Ladanyi M. The nuclear deubiquitinase BAP1 is commonly inactivated by somatic mutations and 3p21.1 losses in malignant pleural mesothelioma. Nat Genet 2011;43:668-72.

[25] Yoshikawa Y, Sato A, Tsujimura T, Emi M, Morinaga T, Fukuoka K, Yamada S, Murakami A, Kondo N, Matsumoto S, Okumura Y, Tanaka F, Hasegawa S, Nakano T, Hashimoto-Tamaoki T. Frequent inactivation of the BAP1 gene in epithelioid-type malignant mesothelioma. Cancer Sci 2012;103:868-

74.

[26] Nasu M, Emi M, Pastorino S, Tanji M, Powers A, Luk H, Baumann F, Zhang YA, Gazdar A, Kanodia S, Tiirikainen M, Flores E, Gaudino G, Becich MJ, Pass HI, Yang H, Carbone M. High Incidence of Somatic BAP1 alterations in sporadic malignant mesothelioma. J Thorac Oncol 2015;10:565-76.

[27] Lo Iacono M, Monica V, Righi L, Grosso F, Libener R, Vatrano S, Bironzo P, Novello S, Musmeci L, Volante M, Papotti M, Scagliotti GV. Targeted next-generation sequencing of cancer genes in advanced stage malignant pleural mesothelioma: a retrospective study. J Thorac Oncol 2015;10:492-9.

[28] Emi M, Yoshikawa Y, Sato C, Sato A, Sato H, Kato T, Tsujimura T, Hasegawa S, Nakano T, Hashimoto-Tamaoki T. Frequent genomic rearrangements of BRCA1 associated protein-1 (BAP1) gene in Japanese malignant mesothelioma-characterization of deletions at exon level. J Hum Genet 2015;60:647-9.

[29] Bueno R, Stawiski EW, Goldstein LD, Durinck S, De Rienzo A, Modrusan Z, Gnad F, Nguyen TT, Jaiswal BS, Chirieac LR, Sciaranghella D, Dao N, Gustafson CE, Munir KJ, Hackney JA, Chaudhuri A, Gupta R, Guillory J, Toy K, Ha C, Chen YJ, Stinson J, Chaudhuri S, Zhang N, Wu TD, Sugarbaker DJ, de Sauvage FJ, Richards WG, Seshagiri S. Comprehensive genomic analysis of malignant pleural mesothelioma identifies recurrent mutations, gene fusions and splicing alterations. Nat Genet 2016;48:407-16.

[30] Ascoli V, Romeo E, Carnovale Scalzo C, Cozzi I, Ancona L, Cavariani F, Balestri A, Gasperini L, Forastiere F. Familial malignant mesothelioma: a population-based study in central Italy (1980-2012). Cancer Epidemiol 2014;38:273-8.

[31] Abdel-Rahman MH, Rai K, Pilarski R, Davidorf FH, Cebulla CM. Germline BAP1 mutations misreported as somatic based on tumor-only testing. Fam Cancer 2016;15:327-30.

[32] Gerami P, Yelamos O, Lee CY, Obregon R, Yazdan P, Sholl LM, Guitart GE, Njauw CN, Tsao H. Multiple Cutaneous Melanomas and Clinically Atypical Moles in a Patient With a Novel Germline BAP1 Mutation. JAMA Dermatol 2015;151:1235-9. 
[33] Wiesner T, Obenauf AC, Murali R, Fried I, Griewank KG, Ulz P, Windpassinger C, Wackernagel W, Loy S, Wolf I, Viale A, Lash AE, Pirun M, Socci ND, Rutten A, Palmedo G, Abramson D, Offit K, Ott A, Becker JC, Cerroni L, Kutzner H, Bastian BC, Speicher MR. Germline mutations in BAP1 predispose to melanocytic tumors. Nat Genet 2011;43:1018-21.

[34] Njauw CN, Kim I, Piris A, Gabree M, Taylor M, Lane AM, DeAngelis MM, Gragoudas E, Duncan LM, Tsao H. Germline BAP1 inactivation is preferentially associated with metastatic ocular melanoma and cutaneous-ocular melanoma families. PLoS One 2012;7:e35295.

[35] Hoiom V, Edsgard D, Helgadottir H, Eriksson H, All-Ericsson C, Tuominen R, Ivanova I, Lundeberg J, Emanuelsson 0, Hansson J. Hereditary uveal melanoma: a report of a germline mutation in BAP1. Genes Chromosomes Cancer 2013;52:378-84.

[36] Cheung M, Talarchek J, Schindeler K, Saraiva E, Penney LS, Ludman M, Testa JR. Further evidence for germline BAP1 mutations predisposing to melanoma and malignant mesothelioma. Cancer Genet;206:206-10.

[37] Farley MN, Schmidt LS, Mester JL, Pena-Llopis S, Pavia-Jimenez A, Christie A, Vocke CD, Ricketts CJ, Peterson J, Middelton L, Kinch L, Grishin N, Merino MJ, Metwalli AR, Xing C, Xie XJ, Dahia PL, Eng C, Linehan WM, Brugarolas J. A novel germline mutation in BAP1 predisposes to familial clear-cell renal cell carcinoma. Mol Cancer Res 2013;11:1061-71.

[38] Mashtalir N, Daou S, Barbour H, Sen NN, Gagnon J, Hammond-Martel I, Dar HH, Therrien M, Affar el B. Autodeubiquitination protects the tumor suppressor BAP1 from cytoplasmic sequestration mediated by the atypical ubiquitin ligase UBE2O. Mol Cell 2014;54:392-406.

[39] Hakiri S, Osada H, Ishiguro F, Murakami H, Murakami-Tonami Y, Yokoi K, Sekido Y. Functional differences between wild-type and mutant-type BRCA1-associated protein 1 tumor suppressor against malignant mesothelioma cells. Cancer Sci 2015;106:990-9.

[40] Cigognetti M, Lonardi S, Fisogni S, Balzarini P, Pellegrini V, Tironi A, Bercich L, Bugatti M, Rossi G, Murer B, Barbareschi M, Giuliani S, Cavazza A, Marchetti G, Vermi W, Facchetti F. BAP1 (BRCA1associated protein 1) is a highly specific marker for differentiating mesothelioma from reactive mesothelial proliferations. Mod Pathol 2015;28:1043-57.

[41] Bi M, Zhao S, Said JW, Merino MJ, Adeniran AJ, Xie Z, Nawaf CB, Choi J, Belldegrun AS, Pantuck AJ, Kluger HM, Bilguvar K, Lifton RP, Shuch B. Genomic characterization of sarcomatoid transformation in clear cell renal cell carcinoma. Proc Natl Acad Sci U S A 2016;113:2170-5.

[42] Goh AM, Coffill CR, Lane DP. The role of mutant p53 in human cancer. J Pathol 2011;223:116-

26.

[43] Chenevix-Trench G, Spurdle AB, Gatei M, Kelly H, Marsh A, Chen X, Donn K, Cummings M, Nyholt D, Jenkins MA, Scott C, Pupo GM, Dork T, Bendix R, Kirk J, Tucker K, McCredie MR, Hopper JL, Sambrook J, Mann GJ, Khanna KK. Dominant negative ATM mutations in breast cancer families. J Natl Cancer Inst 2002;94:205-15.

[44] Machida YJ, Machida Y, Vashisht AA, Wohlschlegel JA, Dutta A. The deubiquitinating enzyme BAP1 regulates cell growth via interaction with HCF-1. J Biol Chem 2009;284:34179-88.

[45] Betti M, Aspesi A, Biasi A, Casalone E, Ferrante D, Ogliara P, Gironi LC, Giorgione R, Farinelli P, Grosso F, Libener R, Rosato S, Turchetti D, Maffe A, Casadio C, Ascoli V, Dianzani C, Colombo E, Piccolini E, Pavesi M, Miccoli S, Mirabelli D, Bracco C, Righi L, Boldorini R, Papotti M, Matullo G, Magnani C, Pasini B, Dianzani I. CDKN2A and BAP1 germline mutations predispose to melanoma and mesothelioma. Cancer Lett 2016;378:120-30. 


\section{Legend to Figures}

Figure 1 BAP1 immunostaining (brown chromogen). A, B, and C) Epithelioid mesothelioma cells show the loss of nuclear expression associated with a granular staining of the cytoplasm (cases: C-II-1; C-II2; G-II-6). D) Sarcomatoid mesothelioma cells show staining heterogeneity: cells retaining nuclear staining are intermingled with others showing the loss of nuclear expression, and strong and diffuse cytoplasmic reactivity (Case: G-II-8).

Figure 2 BAP1 immunostaining and BAP1 sequencing in case D-II-4 (biphasic mesothelioma). A) Absence of nuclear staining in epithelioid cells. B) Retained nuclear staining in $>75 \%$ of sarcomatoid cells. C) Forward electopherograms depicting a non-frameshifit InDel of BAP1 in heterozygosis (exon 5: c.329_335delinsTC) in both epithelioid and sarcomatoid DNA with different allelic frequency. Normal patient's tissue and wild-type sequences of exon 5 are shown for comparison. WT, wild-type sequence; N, normal tissue DNA; T-Epit, epithelial DNA; T-Sarc, sarcomatoid DNA. 
Table 1 Clinical information, histopathological and genetic findings in 4 families with multiple cases of malignant mesothelioma

\begin{tabular}{|c|c|c|c|c|c|c|c|c|c|}
\hline \multirow[b]{2}{*}{ Familya } & \multirow[b]{2}{*}{ Case } & \multirow[b]{2}{*}{$\begin{array}{l}\text { Gender/Age } \\
\text { at diagnosis }\end{array}$} & \multirow{2}{*}{\multicolumn{2}{|c|}{ Histology }} & \multirow[b]{2}{*}{$\begin{array}{c}B A P 1 \text { tumor sequencing } \\
\text { status }\end{array}$} & \multicolumn{4}{|c|}{ BAP1 Immunostaining } \\
\hline & & & & & & Nucleus & $\begin{array}{c}\text { \% stained } \\
\text { cells }\end{array}$ & Cytoplasm & $\%$ stained cells \\
\hline \multirow{2}{*}{$\mathrm{Co}^{\mathrm{O}}$} & II-1 & M-69 & \multicolumn{2}{|c|}{ Epithelioid } & No testing done & Negative & - & Positive-strong & $>75$ \\
\hline & II-2 & M-66 & \multicolumn{2}{|c|}{ Epithelioid } & No mutation & Negative & - & Positive-strong & $>75$ \\
\hline \multirow{3}{*}{$\mathrm{D}^{0}$} & II-3 & M-66 & \multicolumn{2}{|c|}{ Epithelioid } & No testing done & Negative & - & Positive-faint & $>75$ \\
\hline & \multirow{2}{*}{ II-4 } & \multirow{2}{*}{ M-70 } & \multirow{2}{*}{ Biphasic } & epithelioid & c.329_335delinsTC & Negative & - & Positive-faint & $25-75$ \\
\hline & & & & sarcomatoid & c.329_335delinsTCb & Negative & $25^{c}$ & Positive-faint & 25 \\
\hline \multirow{3}{*}{$\mathrm{G}^{\mathrm{H}}$} & II-6 & F-63 & \multicolumn{2}{|c|}{ Epithelioid } & No mutation & Negative & - & Positive-strong & $>75$ \\
\hline & II-8 & $\mathrm{M}-55$ & \multicolumn{2}{|c|}{ Sarcomatoid } & No testing done & Negative & $25-75^{\mathrm{d}}$ & Positive-strong & $25-75$ \\
\hline & II-9 & M-56 & \multicolumn{2}{|c|}{ Sarcomatoid } & \multicolumn{5}{|c|}{ No testing done $\mathrm{e}^{\mathrm{e}}$} \\
\hline \multirow{2}{*}{$\mathrm{O}^{\mathrm{Uk}}$} & II-3 & M-78 & \multicolumn{2}{|c|}{ Epithelioidf } & No testing done & Negative & - & Positive-faint & $>75$ \\
\hline & III-1 & F-45 & \multicolumn{2}{|c|}{ Epithelioid } & No mutation & Negative & - & Positive-faint & $>75$ \\
\hline
\end{tabular}

${ }^{a}$ Ascoli, et al 2014 [29]; Asbestos exposure circumstances: O, occupational; H, household; Uk, unknown (interview available)

${ }^{b}$ Lower allelic frequency in respect to the epithelioid component of the same tumor (Figure 2C)

${ }^{c}$ The fraction of cells with retained BAP1 nuclear staining showed negative cytoplasmic reactivity (Figure 2B)

$\mathrm{d}$ The fraction of cells with retained BAP1 nuclear staining showed negative cytoplasmic reactivity (Figure 1D)

e No tissue specimen was available

f Peritoneal mesothelioma

F, female; M, male 
TABLE 2. Families with Multiple cases of Malignant Mesothelioma, History of Cancer and Asbestos Exposure Analyzed for BAP1 Germline Mutations

\begin{tabular}{|c|c|c|c|c|c|}
\hline & $\begin{array}{c}\text { Families } \\
(n=46)\end{array}$ & $\begin{array}{c}\text { BAP1 } \\
\text { unmutated } \\
(n=20)\end{array}$ & Reference(s) & $\begin{array}{c}\text { BAP1 } \\
\text { mutated } \\
(n=26)\end{array}$ & Reference(s) \\
\hline \multicolumn{6}{|l|}{ History of cancer } \\
\hline Common TPDS $^{\text {a }}$ cancer & 21 & 1 & {$[8]$} & 20 & {$[2-6,8,10-16,22]$} \\
\hline Other cancer $^{b}$ & 12 & 9 & {$[8-9,18]$ present study } & 3 & {$[8-9,22]$} \\
\hline Negative & 5 & 2 & [8-9] present study & 3 & [7-9] \\
\hline Missing data & 8 & 8 & [17] & 0 & - \\
\hline \multicolumn{6}{|l|}{ Asbestos Exposure } \\
\hline Yes & 23 & 16 & {$[9,17-18]$ present study } & 7 & {$[3-4,9,13-14,22]$} \\
\hline No & 3 & 0 & - & 3 & {$[5,7,15]$} \\
\hline Missing data & 20 & 4 & [8] present study & 16 & {$[2,6,8,10-12,16]$} \\
\hline
\end{tabular}

${ }^{a}$ TPDS, tumor predisposition syndrome (OMIM, \#614327)

${ }^{\mathrm{b}}$ Leukemia, prostate, lung, thyroid, breast, larynx, colon, stomach, pancreas (BAP1 unmutated families); Breast, salivary gland, stomach, throat (BAP1 mutated families). Some authors report breast cancer as potential BAP1 syndrome-related cancer [22] 